\title{
Impact of Climate Change and Technology Adoption on Cereal Yields in South Asian Countries
}

\author{
Shahzad Alvi* ${ }^{1}$, Faisal Jamil ${ }^{2}$
}

\begin{abstract}
Over the past decade, scientists and economists have shown consensus that agricultural production is at high stake due to climatic changes. Crops are hit by droughts, floods, heavy or low levels of rainfall, humidity, decreasing water resources and increasing wind storms. On the other side, farmers are adopting new technology, which upholding the agricultural production. Considering these aspects, the present study examines the impact of climate change and technology adoption on cereal yields in South Asian countries. We develop an economic model that incorporates technology adoption, which is exogenously determined by farmers' characteristics and market structure. Using the time series data from 1990 to 2015, we apply GMM econometric technique. The estimated results indicate that climate change decreases the cereal yields while the technology adoption increases the cereal yields. But the slow pace of technology adoption in the agriculture sector is a challenge to meet the food demand of the growing population in South Asian countries. This study suggests that these countries should increase the use of advanced technology and practices in agriculture sector to get sustainability in food production. Besides, there is the incessant need to reduce GHG emissions and population growth.
\end{abstract}

Key words: Climate change; Technology adoption; Cereal yields; South Asia; Food sustainability

\section{Introduction}

There is a general consensus among the agricultural scientists and economists that agricultural production and crop yields are at high stake due to climatic changes during the past few decades. Crops are hit by frequent spells of droughts, floods, heavy or low levels of rainfall, humidity, decreasing water resources and increasing wind storms. These climatic changes can create a shortage of food and cause famines in the future, especially, in the developing countries, which have fewer resources and are lagging behind in the cereal yields as compare to the developed countries. Decrease in food production due to climate change can be worsened in South Asian and African countries who are already facing large undernourished population (World Bank, 2017). The menace of climate change is expected to deteriorate the situation of undernourishment in the upcoming years. As, it affects food production directly through changes in agro-ecological conditions and indirectly by affecting the growth and distribution of incomes.

Despite the fact that climate change damages crops, farmers are adopting new technology. Adoption of improved technology and seeds and modified farming'

\footnotetext{
${ }^{1 *}$ School of Social Sciences and Humanities, National University of Sciences and Technology, Islamabad, Pakistan.

${ }^{2}$ School of Social Sciences and Humanities, National University of Sciences and Technology, Islamabad,

Pakistan.
} 
practices uphold the cereal yields. One might view that there is not much need to worry about climate change because of the growing use of modern practices. It will make possible that World can feed itself with less land and lower carbon emissions (Henderson and Cochrane, 2017).

Over the past decade, a growing body of economics research has estimated the impacts of climate change on agriculture. Given the natural relationship between climatic factors and plant growth, the agricultural sector is thoroughly researched; Bosello et al. (2006); Chen et. al (2016) Deschênes and Greenstone (2007); Kjellstrom, et al. (2009); Mendelsohn et al. (2016); Roson and Sartori (2016); Schlenker et al. (2017); Tol (2002); Zhang et al. (2017) ). However, the majority of studies focus on climatic variables by including temperature and precipitation, but largely ignoring the role of technology adoption in time series studies. Omitting variables capturing technology adoption may result biased estimates.

This study examines the impact of climate change and technology adoption on cereal yields in vulnerable South Asian countries namely; Bangladesh, India and Pakistan. Given the importance of technology adoption in agriculture production, this study examines the impact of climatic changes and technology adoption on cereal yields in these countries. We derive an economic model that incorporate technology adoption, which is exogenously determined by farmers' characteristics and market structure. Using the time series data from 1990 to 2015, we have applied GMM econometric technique. The estimated results indicate that climate change is decreasing the cereal yields that is counterbalanced by the technology adoption.

This study is organized as follows. Section 2 presents the model and data. Section 3 analyses the results, and Section 4 concludes the study and gives policy suggestions

\section{Research methodology and data}

\subsection{Theoretical model}

There are finite numbers of rational that is utility maximizing farmers. It is assumed that the production function for any point in time for farmers is of CobbDouglas form.

$$
Y_{i t}=e^{\beta_{t}}\left(\prod_{j=1}^{k} X_{i j t}^{\gamma_{j}}\right) e^{u_{i t}}
$$

where, $Y_{i t}$ is cereals yield, $X_{i j t}$ is a vector of climatic and other inputs such as, temperature, precipitation, seeds and fertilizer etc. where, $X_{j}=\left(X_{1}, X_{2} \ldots . X_{K}\right) . \gamma$ is parameters of $X_{i j t}$ 's. As climatic variability increases the risk of yield, farmers would change their practices and technologies that essentially minimize the climatic risks and increase the yield. It is assumed that the farmers have two options, either to adopt new technology or stick with traditional farming practices. The production function for farmers under the use of technology and non-use of technology are as follows.

$$
Y_{i t}^{H}=e^{\beta_{t}^{H}}\left(\prod_{j=1}^{k} X_{i j t}^{\gamma_{j}^{H}}\right) e^{u_{i t}^{H}}
$$




$$
Y_{i t}^{N}=e^{\beta_{t}^{N}}\left(\prod_{j=1}^{k} X_{i j t}^{\gamma_{j}^{N}}\right) e^{u_{i t}^{N}}
$$

The outcome $Y_{i t}^{H}$ and $Y_{i t}^{N}$ are the yields (output per hectare) at time $t$ when farmer $i$ uses new technology and traditional technology respectively. Throughout, $H$ is used to represent new technology and $N$ the use of traditional technology.

Taking $\log$ of Equations (2) and (3)

$$
\begin{aligned}
& y_{i t}^{H}=\beta_{t}^{H}+X_{i j t}^{\prime} \gamma_{j}^{H}+u_{i t}^{H} \\
& y_{i t}^{N}=\beta_{t}^{N}+X_{i j t}^{\prime} \gamma_{j}^{N}+u_{i t}^{N}
\end{aligned}
$$

where, $y_{i t}^{H}$ and $y_{i t}^{N}$ are the log of yields, $X_{i t}^{\prime}$ is $\log$ of the inputs. The gain in yields from new technology is given Equation (6).

$$
B_{i t}=y_{i t}^{H}-y_{i t}^{N}=\beta_{t}^{H}-\beta_{t}^{N}+X_{i j t}^{\prime}\left(\gamma_{j}{ }^{H}-\gamma_{j}{ }^{N}\right)+u_{i t}^{H}-u_{i t}^{N}
$$

This framework enables us to think the determinants of technology adoption. It would be based on comparing the yields under the choice of adopting or non-adoption of technology such that,

$$
\begin{gathered}
h_{i t}=1 ; \text { if } \quad y_{i t}^{H}>y_{i t}^{N} \\
h_{i t}=0 ; \text { if } y_{i t}^{H}<y_{i t}^{N}
\end{gathered}
$$

where $h_{i t}=1$, when farmers use technology and $h_{i t}=0$ when farmers don't use technology. These types of selection implications are used by Roy (1951) and Heckman and Honors (1990) in wage and benefits model respectively. Equation (8) presents the implications of strict Roy model.

$$
\frac{y_{i t}^{H}}{y_{i t}^{N}}>1 \text { for } h_{i t}=1 \text { and } \frac{y_{i t}^{H}}{y_{i t}^{N}} \leq 1 \text { for } h_{i t}=0
$$

It is imposed comparative advantage between the adoption and non-adoption of technology.

In Roy model setup, the use of technology is based on comparison of yields under adoption and non-adoption of technology. But the adoption of technology is based on some other observables and un-observable factors. The farmers are assumed to be risk neutral. The use of technology is dependent on other factors that are not in the yield equation. These factors may include the availability and affordability of advance technology (e.g. pesticides and quality seeds etc.), farmer's skills to utilize them and government policies etc. (Suri, 2011). These are the components over and above the $X_{i t}$ 's that are in the yield equation that affect the use of technology periodically. Due to these components, the use of technology will generally be correlated with errors in the equation. Putting other factors which are not in the yield equation is not so easy and there would be standard selection error problem. Now, we place additional structure on unobserved productivities and impose factor structure following (Lemieux, 1998)

$$
\begin{aligned}
& u_{i t}^{H}=\theta_{i t}^{H}+\xi_{i t}^{H} \\
& u_{i t}^{N}=\theta_{i t}^{N}+\xi_{i t}^{N}
\end{aligned}
$$


$\theta_{i t}^{H}$ and $\theta_{i t}^{N}$ are unobserved components, which determine the use of technology. The $\xi_{i t}^{H}$ and $\xi_{i t}^{N}$ are assumed to be uncorrelated with each other, as well as with the $X_{i t}$ 's unlike the $\theta_{i t}^{H}$ and $\theta_{i t}^{N}$. This assumption amounts to transitory errors $\xi_{i t}^{H}$ and $\xi_{i t}^{N}$ not being to affect the use of technology, although $\theta_{i t}^{H}$ and $\theta_{i t}^{N}$ are known and can affect the use of technology. $\xi_{i t}^{H}$ and $\xi_{i t}^{N}$ are not known. Following Heckman and Honore (1990), Lemieux (1998) and others, the linear projections of the $\theta_{i t}^{H}$ and $\theta_{i t}^{N}$ on $\left(\theta_{i t}^{H}-\theta_{i t}^{N}\right)$ is given as follow.

and

$$
\theta_{i t}^{H}=b_{H}\left(\theta_{i t}^{H}-\theta_{i t}^{N}\right)+\tau_{i}^{H}
$$

$$
\theta_{i t}^{N}=b_{N}\left(\theta_{i t}^{H}-\theta_{i t}^{N}\right)+\tau_{i}^{N}
$$

where, $b_{H}$ and $b_{N}$ are the projection coefficients. The gain $\left(\theta_{i t}^{H}-\theta_{i t}^{N}\right)$, can be redefine

to be farmer-specific comparative advantage, $\Pi$, for non- adoption as

$$
\Pi_{i t} \equiv\left(\theta_{i t}^{H}-\theta_{i t}^{N}\right)
$$

Put equation (13) into (12) we get

$$
\theta_{i t}^{N}=b_{N} \Pi_{i t}+\tau_{i}^{N}
$$

Similarly, we can redefine for the technology projection in case of technology adoption by doing little algebraic work.

$$
\theta_{i t}^{H}=b_{H}\left(\theta_{i t}^{H}-\theta_{i t}^{N}\right)+\tau_{i}^{H}
$$

or

$$
\theta_{i t}^{H}=b_{H} \Pi_{i t}+\tau_{i}^{H}
$$

Plugging equation (14) and (16) into (10) and (9), we get

and

$$
u_{i t}^{H}=b_{H} \Pi_{i t}+\tau_{i}^{H}+\xi_{i t}^{H}
$$

$$
u_{i t}^{N}=b_{N} \Pi_{i t}+\tau_{i}^{N}+\xi_{i t}^{N}
$$

Put equations (17) and (18) into (4) and (5) respectively yields,

and

$$
y_{i t}^{H}=\beta_{t}^{H}+X_{i j t}^{\prime} \gamma_{j}^{H}+b_{H} \Pi_{i t}+\tau_{i}^{H}+\xi_{i t}^{H}
$$

$$
y_{i t}^{N}=\beta_{t}^{N}+X_{i j t}^{\prime} \gamma_{j}^{N}+b_{N} \Pi_{i t}+\tau_{i}^{N}+\xi_{i t}^{N}
$$

We take generalized yield function of the form.

$$
y_{i t}=h_{i t} y_{i t}^{H}+\left(1-h_{i t}\right) y_{i t}^{N}
$$

Where, $h_{i t}$ is in binary form, 0 and 1 .

By substitute equations (19) through (20) into generalized equation (21) to derive

$$
\begin{gathered}
y_{i t}=\beta_{t}^{N}+\left(\beta_{t}^{H}-\beta_{t}^{N}\right) h_{i t}+X_{i j t}^{\prime} \gamma^{N}+X_{i t}^{\prime}\left(\gamma_{j}{ }^{H}-\gamma_{j}^{N}\right) h_{i t}+b_{N} \Pi_{i t} \\
+\left(b_{H}-b_{N}\right) \Pi_{i t} h_{i t}+a_{i}+\varepsilon_{i t}
\end{gathered}
$$


where, $\left(b_{H}-b_{N}\right)$ is the coefficient of farmers' comparative advantages components from use of technology. $\varepsilon_{i t}=\xi_{i t}^{N}+h_{i t}\left(\xi_{i t}^{H}-\xi_{i t}^{N}\right)$ is assumed to be unanticipated component in yields. $\tau_{i}^{N}+\left(\tau_{i}^{H}-t_{i}^{N}\right) h_{i t}=a_{i}$.

The quantity of seeds and fertilizer and other inputs are fixed in per-hectare and extensive use of these inputs may cause to decrease the yield. The farmers use inputs in optimal amounts and presumably that all inputs have same potential (Foster and Rosenzweig, 2010) It is assumed that the constant is time variant, $\beta_{t}^{N}+h_{i t}\left(\beta_{t}^{H}-\beta_{t}^{N}\right)$. Thus, by incorporating above assumption, we can rewrite equation (22) as follows Which is the Fixed Effects model.

$$
y_{i t}=X_{i j t}^{\prime} \gamma+\Pi_{i t} Z_{i j t}+\beta_{t}+a_{i}+\varepsilon_{i t}
$$

$Z_{i j t}$ is technology which is determine exogenously. Equation (23) implies that yield is only depended on climatic variability and adoption of technology that is exogenously determine by unobserved but known characteristics.

\subsection{Empirical model}

To assess the impacts of climate change on crop yield, we use an econometric model that incorporates climatic and other non-climatic variables. Let $i$ index country, $t$ index year and $c$ index crop. Crop yields $(\mathrm{kg} / \mathrm{ha})$ are related to climate and other nonclimate variables. We used the growing degree days instead of average temperature. Because the use of average temperature for the entire season or month can hide the extreme temperature during the growing period of specific crop (Schlenker and Roberts, 2009). Thus, the regression with growing season can be written as follows.

$$
\begin{gathered}
\log Y_{i t}=\int_{\underline{t}}^{\bar{t}} g(T) \varphi_{i t}(T) d T+\gamma_{1}^{\prime}\left(\text { Prep }_{i t}\right)+\gamma_{2}\left(\text { Hum }_{i t}\right)+\gamma_{3}\left(\text { Wind }_{i t}\right) \\
+\Pi\left(\text { Tech }_{i t}\right)+\beta_{t}+a_{i}+\varepsilon_{i t}
\end{gathered}
$$

Where $Y$ is crop yield, $g(T)$ is the growth function of crop that depends on temperature, T. whereas, $\bar{t}$ and $\underline{t}$ is the upper and lower bound of temperature, prep is vector of precipitation that include both linear and quadratic form of precipitation, Hum is humidity and Wind is average wind speed. Here, we assume that crops growing seasons remained unchanged over the study period for each country. Tech is technology adoption in the agriculture sector.

As, technology adoption is endogenous and determine exogenously. It is indicating that $\operatorname{Cov}($ Tech, $\varepsilon) \neq 0$, The motivation of adoption is determined through education and income of farmers. when endogenous variable is determined exogenously and in some omitted variables give biased results. It is often referred to as instrument exogeneity. The instrument variable relies on two condition. Firstly, it is correlated with endogenous variable and secondly, it is not correlated with error term (Heckman et al., 2001). We estimated Equation (24) with instrument condition separately for wheat, rice and maize. This study take level of education (Edu) and income (Inc) as farmers' characteristics of a country. A time-invariant country fixed effect $a_{i}$ is used to control for regional 
heterogeneity. $\beta_{t}$ is the time effect which is introduced to capture the other development over the time period, such as improvement in seeds quality and farmer's practices.

\subsection{Data and variable description}

\section{Weather variables}

The present study used the growing degree days (GDD) instead of average temperature. GDD is the sum of heat that a crop receives over the growing period between lower and upper thresholds. The upper and lower thresholds are still in debate for each crop. By following (Schlenker and Roberts, 2009), (Chen et al., 2016) Chen et al. (2016) and Zhang et al. (2017), the current study used $8^{\circ} \mathrm{C}$ as lower threshold and $30^{\circ} \mathrm{C}$ is upper threshold level. The growing degree days are calculated from the average daily temperature in the growing season for each crop is as following ${ }^{1}$.

$$
g(T)= \begin{cases}0 & \text { if } T \leq 8 \\ T-8 & \text { if } 8<T<30 \\ 22 & \text { if } 30 \leq T\end{cases}
$$

To capture the non-linear of $G D D_{8.30}$, a quadratic form of $G D D_{8.30}$ is included. As above threshold, $30^{\circ} \mathrm{C}$ is considered harmful for the crops, a separate variable, $G D D_{30+}$ is also included.

This study has used cumulative precipitation and relative humidity and average wind speed along with GDD in the growing season for each crop. For non-linear, a quadratic variable of precipitation is also introduced. The data of climatic variables are obtained from NASA-POWER (power.larc.nasa.gov) for the period of 1990 to 2015. NASAPOWER provides satellite and model-derived agrometeorological data on a $1^{\circ}$ latitude and $1^{\circ}$ longitude grid with global coverage.

\section{Cereal Productions}

The data on cereals production including, wheat, rice and maize yield per hectare for each country is obtained from the Food and Agriculture organization (FAO) for the period of $1990-2015^{2}$.

\section{Use of technology}

The use of technology variable is proxied by use of electric and machinery in agriculture sector. The use of electric and machinery data is collected from Eora MRIO (http://worldmrio.com/). The Eora global supply chain database consists of a multiregion input-output table (MRIO) model that provides a time series of high-resolution input and output table from 1990 to 2015.

\footnotetext{
${ }^{1}$ Growing season for the rice, maize and wheat is different across the south Asian countries. For example, rice crop sowing and harvesting dates are different in Pakistan compared to Bangladesh. The present study use different growing seasons for each crop and country.

2 Although, county level data is good to capture the impact of climate change on agriculture production, but due to non-availability of data and its inconsistency over the time period at county level across the south Asian countries, we use country level data. To make climatic variables and cereal yields data consistent with each other, we used satellite scan that give us the areas in which a specific crop is growing. By using the satellite images.
} 


\section{Endogeneity of the Socioeconomic Development}

It is evident that use of technology increases with the growing level of socioeconomic development. Education and income levels of farmers increases their likelihood of adopting advanced technology as compared to farmers who have less education and income. Use of technology is endogenous and to address the issue of endogeneity, this study uses education and income as instrumental variables (Di-Falco, 2014; Suri, 2011). The data on average year of schooling and per capital income is obtained from the World Bank (2017) from 1990 to 2015.

\section{Results and discussion}

We start a panel data analysis by applying GMM (Generalized Method of Moments). The GMM estimator is typically used to correct for bias caused by endogenous explanatory variables. For this, we have performed Durbin-Wu-Hausman test of endogeneity where, null hypothesis is that variable is exogenous. The $p$-value of chi-squares is less than $5 \%$, hence we reject the null hypothesis. There are two conditions for an instrumental variable to be included. One is that, it must be correlated with the variable that needs to be instrumented. Second, it must be uncorrelated with error term (Wooldridge, 2002). In our case, use of technology is exogenous, which cause the problem of endogeneity. Our dependent variables are maize, rice and wheat yields per hectare, while independent variables are growing degree days, precipitation, humidity and use of technology. The results are given in Table 1.

The results indicate that the growing temperature or degree days $\left(G^{2} D_{8.30}\right)$ affects maize, rice and wheat crops. The relationship between $\mathrm{GDD}_{8.30}$ and yield of maize, rice and wheat is inverted U-shaped. In the present study, we have introduced the square of GDD $_{8.30}$ to capture the nonlinearity. The coefficient of $\mathrm{GDD}_{8.30}$ squared is significant which is indicating that nonlinear relationship is exiting and $\mathrm{GDD}_{8.30}$ increases the yields but at declining rates. Temperature above $30^{\circ} \mathrm{C}$ is harmful and negatively affecting all three crop yields. The relationship between precipitation and crop yields are also nonlinear. Which is indicating that increase in the precipitation up to moderate level is useful. While, a low or higher level of precipitation is destructive for crops. The coefficient of precipitation and its square is significant for the three crops. Humidity has a positive impact on rice and wheat yields. However, it is insignificant in the case of maize yields. The findings of this study are consistent with the findings of Schlender and Roberts (2009) for the USA, and Chen et al (2016) Zhang et al. (2017) for the China. The coefficient of wind speed is negative, but insignificant, it may be due to the geographical location of south Asian countries, where, the Indian Oceans Basin doesn't spawn many cyclones. The results indicate that the use of technology in agriculture sector in South Asia is increasing the yields of all three crops. The coefficient of technology adoption is significant for all three crops and it more positively affects the wheat yields. 
Table 1: Results impact of climate change and technology adoption on cereal yields

\begin{tabular}{llll}
\hline Variable & Maize & Rice & Wheat \\
\hline GDD $_{8.30}$ & $0.273^{* * *}$ & $0.310^{* *}$ & $0.341^{* *}$ \\
GDD $_{8,30}^{2}$ & $(0.0023)$ & $(-0.038)$ & $(0.014)$ \\
& $-0.085^{* * *}$ & $-0.073^{* *}$ & $-0.052^{* * *}$ \\
GDD $_{30+}$ & $(0.001)$ & $(0.026)$ & $(0.001)$ \\
& $-0.080^{*}$ & $-0.083^{* *}$ & $-0.069^{* * *}$ \\
Precipitation & $(0.067)$ & $(0.012)$ & $(0.002)$ \\
& $0.042^{* *}$ & $0.081^{* * *}$ & $0.07 * * *$ \\
Precipitation & $(0.043)$ & $(0.007)$ & $(0.009)$ \\
& $-0.033^{* *}$ & $-0.02^{* *}$ & $-0.051^{*}$ \\
Humidity & $(0.039)$ & $(0.026)$ & $(0.084)$ \\
& 0.005 & $0.003^{* *}$ & $0.0020^{*}$ \\
Wind Speed & $(0.141)$ & $(0.03)$ & $(0.06)$ \\
& -0.056 & -0.013 & -0.001 \\
Technology & $(0.320)$ & $(0.222)$ & $(0.159)$ \\
F-Statistics & $0.25^{* * *}$ & $0.211^{* * *}$ & $0.294^{* * *}$ \\
R-Square & $(0.00)$ & $(0.005)$ & $(0.00)$ \\
Durbin-Wu-Hausman test & $10.12^{* * *}$ & $15.89^{* * *}$ & $11.21^{* * *}$ \\
& 69.19 & 65.12 & 64.45 \\
Note*** $* *$ & 5.19 & 6.12 & 5.78
\end{tabular}

Note: ***, ** and * shows significance at 99\%, 95\% and 90\% confidence interval. $p$-value is in parentheses.

Future climate change impacts on Cereal Yields

To calculate the future impacts of climate change on yields, first, we calculate the average difference of past climatic variables (1990-2015) and future (2070-2099) climatic variables. We then use the climatic variables coefficients based on equation (24) to calculate the impacts of future climate change on maize, rice and wheat yields by using simple multiplication. In the last, we add the impacts of all climate variables to check the total impact of climate change on crop yields. The data of future climate change or prediction come from the Handley Centre's third Coupled Ocean-Atmosphere General Circulation Model (HadCM3). Which is used in the IPCC report 2007. HadCM3 predict average daily temperature, precipitation and relative humidity on a $2.5^{\circ}$ latitude and $3.75^{\circ}$ longitude grid with global coverage. There are four major scenarios (A1FI, A2, B2, B1) of future climate prediction. The A1FI assumes the largest increase in $\mathrm{CO}_{2}$ due to continued use of fossil fuels. While, B1 assumes a decline in $\mathrm{CO}_{2}$ over the next century. Other scenarios are between them. For brevity, here, we have reported the results of 
future impacts of climate change on Maize, rice and wheat under the A1FI scenario in Table- $2^{3}$.

Table 2: Future climate change impacts on yields

\begin{tabular}{llll}
\hline & Maize & Rice & Wheat \\
\hline Only temperature and precipitation & -39.71 & -48.12 & -15.17 \\
Add humidity & -34.01 & -42.15 & -9.89 \\
& & & \\
\hline
\end{tabular}

The climate prediction results indicate $39.71 \%$ loss in maize, $48.12 \%$ in rice and $15.17 \%$ in wheat yields by the end of this century under future temperature and precipitation change. When, we add humidity, then the loss decreases to $34.01 \%$ for maize, $42.15 \%$ for rice and $15.17 \%$ for wheat.

\section{Conclusion.}

This study examined the impact of climatic changes and technology adoption on cereal yields in the vulnerable South Asian countries- Bangladesh, India and Pakistan. We derived model of cereal yields by incorporating climatic variables and the technology adoption, which is exogenously determined by farmers' characteristics. The estimated results indicate that climate change decreases the cereal yields while the technology adoption is increasing the cereal yields. There is the slow pace of technology adoption among the farmers, which is a big challenge to meet the food demand of the growing population in South Asian countries. This study suggests that developing countries should increase the use of advanced technology and improved farming practices to get sustainability in food production. Besides, there is the incessant need to reduce GHG emissions and population growth.

One caveat of the present study is that we used the short run coefficients for studying the long run future impact of climate change on cereal yields. In climate prediction, it is likely to ignore the farmers' adaptation and thus, it overpredict the future impact of climate change. This topic will be left for future research.

\section{Acknowledgement:}

We would like to thank Ather Maqsood Ahmed, Zahid Siddique, Tanweer ul Islam, Iftikhar Hussain Adil, Verda Salman, Shahzada M. Naeem Nawaz and anonymous reviewers for their helpful comments and constructive feedback.

\section{References}

Bosello, F., Roson, R., \& Tol, R. S. J. (2006). Economy-wide estimates of the implications of climate change: Human health. Ecological Economics, 58(3), 579-591.

\footnotetext{
${ }^{3}$ For brevity, here, we have reported the results of future impact of climate change under the A1FI scenario, But the results and graphical presentations of other scenarios and models are available on request.
} 
Chen, S., Chen, X., \& Xu, J. (2016). Impacts of climate change on agriculture: Evidence from China. Journal of Environmental Economics and Management, 76, 105-124. https://doi.org/10.1016/j.jeem.2015.01.005

Deschênes, O., \& Greenstone, M. (2007). The economic impacts of climate change: Evidence from agricultural output and random fuctuations in weather. American Economic Review, 97(1), 354-385. https://doi.org/10.2307/3078074

Di-Falco, S. (2014). Adaptation to climate change in Sub-Saharan agriculture: assessing the evidence and rethinking the drivers, European Review of Agriculture Economics, Vol 41(3), pp. 405-430

Eora (2017) Multi-region input-output table (MRIO) data retrieved from: http://worldmrio.com/countrywise/

FAO stats-Agriculture (2012). Food and Agricultural Organizations of the United Nations. retrieved from: http://www.fao.org/corp/statistics/en/

Handerson D. R \& Cochrane H.J (2017). Climate Change Isn't the End of the World, Wall Street Journal https://www.wsj.com/articles/climate-change-isnt-the-end-of-the-world-1501446277

Heckman, J. \& Honore, B. (1990): The Empirical Content of the Roy Model," Econometrica, 58 (5), 11211149.

Heckman, J. J., Tobias J.L. \& Vytlacil E.. (2001). Four Parameters of Interest in the Evaluation of Social Programs. Southern Economic Journal 68(2):210-233

Foster, A. D., \& Rosenzweig, M. R. (2010). Microeconomics of Technology Adoption. Annual Review of Economics, 2(1), 395-424. https://doi.org/10.1146/annurev.economics.102308.124433

Intergovernmental Panel on Climate Change. (2007). Climate Change 2007: Synthesis Report. In: Pachauri, R.K., Reisinger, A. (Eds.), Contribution of Working Groups I, II and III to the Fourth Assessment Report of the Intergovernmental Panel on Climate Change

Kjellstrom, T., Kovats, R. S., Lloyd, S. J., Holt, T., \& Tol, R. S. J. (2009). The Direct Impact of Climate Change on Regional Labor Productivity. Arcbives of Environmental \& Occupational Health, 64(4), $217-$ 227. https://doi.org/10.1080/19338240903352776

Lemieux, T. (1998). Estimating the Effects of Unions on Wage Inequality in a Panel Data Model with Comparative Advantage and Nonrandom Selection. Journal of Labor Economics, 2(2), 261-291. https://doi.org/10.1086/209889

Mendelsohn, B. R., Nordhaus, W. D., \& Shaw, D. (2016). The Impact of Global Warming on Agriculture : A Ricardian Analysis, The American Economic Review 84(4), 753-771.

NASA-Power (2017) NASA Langley Research Center POWER Project funded through the NASA Earth Science Directorate Applied Science Program https://power.larc.nasa.gov/

Roson, R., \& Sartori, M. (2016). Estimation of Climate Change Damage Functions for 140 Regions in the GTAP 9 Database. Journal of Global Economic Analysis, 1(2), 78-115. https://doi.org/10.21642/JGEA.010202AF

Schlenker, W., Hanemann, W. M., \& Fisher, A. C. (2017). The Impact of Global Warming on U . S . Agriculture : An Econometric Analysis of Optimal Growing Conditions The Review of Economics and Statistics, Vol . 88 , No . 1 (, 88(1), 113-125.

Schlenker, W., \& Roberts, M. J. (2009). Nonlinear temperature effects indicate severe damages to U.S. crop yields under climate change. Proceedings of the National Academy of Sciences, 106(37), 15594-15598. https://doi.org/10.1073/pnas.0906865106

Suri, T. (2011). Selection and Comparative Advantage in Technology Adoption. Econometrica, 79(1), 159-209. https://doi.org/10.3982/ECTA7749

Tol, R. S. J. (2002). Estimates of the damage costs of climate change: Part 1: Benchmark estimates. Environmental and Resource Economics, 21(1), 47-73. https://doi.org/10.1023/A:1014500930521

World Bank (2017). Worl food security group. http://www.worldbank.org/en/topic/food-security

World Bank (2017) Word Development Indicator Data retrieved from: http://databank.worldbank.org/data/

World Economic Forum (2017). Demand of Food, retrieved from: https://www.weforum.org

Wooldridge, J. M. (2002). Econometric analysis of cross section and panel data. Cambridge, Mass: MIT Press

Zhang, P., Zhang, J., \& Chen, M. (2017). Economic impacts of climate change on agriculture: The importance of additional climatic variables other than temperature and precipitation. Journal of Environmental Economics and Management, 83, 8-31. https://doi.org/10.1016/j.jeem.2016.12.001 